\title{
Heterogeneous Consumer Preferences for Native and Invasive Plants: Evidence from Experimental Auctions
}

\author{
Chengyan Yue ${ }^{1,3}$ \\ Departments of Applied Economics and Horticultural Science, University of \\ Minnesota-TC, 1970 Folwell Avenue, St. Paul, MN 55108
}

Terry Hurley ${ }^{2}$

Department of Applied Economics, University of Minnesota-TC, 1970 Folwell Avenue, St. Paul, MN 55108

\author{
Neil O. Anderson ${ }^{2}$ \\ Department of Horticultural Science, University of Minnesota-TC, 1970 \\ Folwell Avenue, St. Paul, MN 55108
}

Additional index words. native plants, invasive plants, willingness to pay, labeling, experimental auction, market segmentation

\begin{abstract}
All stakeholders along the supply chain affect the dispersal of native and invasive horticultural plants. This is especially true for the consumers who determine how the plants are ultimately used. Therefore, consumer attitudes toward native and invasive plants cannot be ignored. This study used an experimental auction to explore market segmentation among consumers in terms of their preference and willingness to pay for labeled native and invasive attributes. We identified three market segments, namely, "nativists" (16\%), "invasive averse" (34\%), and "typical" (50\%) consumers. The three segments of consumers differed in their demographics and attitudes toward native and invasive attributes. From a government policy perspective, labeling invasive or native plants could potentially change the behavior of some consumers, but half of the market is unlikely to be substantially swayed by invasive/native labeling. Therefore, supply-side intervention policies such as sales restrictions may be more effective at promoting native plant purchases and restricting the purchase and spread of invasive plants.
\end{abstract}

Invasive plant dispersals have been strongly affected by the trade and distribution of horticultural plants, primarily by ornamental plants (Anderson and Ascher, 1993; Groves, 1998; Mack, 2003; Mack and Erneberg, 2002; Randall and Marinelli, 1996; Reichard and White, 2001). Many characteristics of today's horticulture industry contribute to increasing the risks of introducing new invasive species into the environment and the likelihood that invasive introductions naturalize (Anderson et al., 2006a, 2006b; Galatowitsch et al., 1999). More than $50 \%$ of invasive plants are ornamentals (Randall and Marinelli, 1996). In general, the horticulture industry selects plants that require little maintenance, have high environmental tolerance, wide adaptability, and consistent performance (Anderson et al., 2006a; Mack, 2005). Consequently, they can be grown worldwide.

Because the ultimate objective of commercial horticultural is to satisfy the desires

\footnotetext{
Received for publication 15 Feb. 2012. Accepted for publication 20 Mar. 2012.

${ }^{1}$ Bachman Endowed Chair in Horticultural Marketing and Assistant Professor.

${ }^{2}$ Associate Professor.

${ }^{3}$ To whom reprint requests should be addressed; e-mail yuechy@umn.edu.
}

of the final consumer (Schaffner et al., 1998), their demand for novel plants drives the industry (Gagliardi and Brand, 2007). Retailers are the intermediaries who, through packaging, transporting, etc., can add value to the products supplied by growers. Although retailer and wholesaler decisions affect the dispersal of invasive or native horticultural plants, consumer decisions are also important and cannot be ignored. Previous economic studies on invasive plants like Kim et al. (2007) and Moffitt and Osteen (2006) focus on governmental and institutional control of the invasion of certain plants, whereas others like Adam et al. (2007) focus on the impact of invasive plants on economic and recreation values. Less effort has been devoted to studying consumer perceptions and valuation of invasive plants. Kelley et al. (2005) studied consumer awareness and knowledge of invasive plants in Philadelphia and found distinct consumer segments; less than half $(41.3 \%)$ thought laws should be passed to prevent the sale of non-native exotic plants. Peters et al. (2006) conducted a survey with horticultural industry professionals and found the majority $(62 \%)$ felt that the invasive plant issue was very important with $89 \%$ directing their customers away from potentially invasive plants. Another $76 \%$ of respondents indicated that they were responsible for educating customers about invasive ornamental plants. Reichard (2005) advocated research to identify the impact of biological invasions to provide scientific support for regulations banning invasive species.

For native plants, Waterstrat et al. (1998) surveyed the U.S. Southern Nurserymen's Association members about their perception of native plants. They found that almost half had increased the quantity and variety of native plants that they purchased and perceived an overall consumer interest in native plants. Brzuszek et al. (2007) explored landscape architectural use of regional native plants in the southeastern United States and found that the designers use a significant amount of regional native plants in their project specifications. The architects also reported that local species were better suited to difficult or unique site conditions. The aforementioned studies suggest that there is a potential to expand the production and marketing of native plants.

Previous studies have shown that consumer demand for product-stewardship or environmentally conscious products and business practices is rapidly rising. Markets consist of different groups of consumers who have different preferences and attitudes toward environment-related product attributes. Consumers with environmental concerns are willing to purchase and pay a premium for environmentally friendly products. These consumers presumably bring profits to companies who conduct environmentally friendly practices (Laroche et al., 2001; Russo and Fouts, 1997). Several studies have investigated the market segmentation for horticulture products and explored consumer attitudes toward environmental issues. For example, Yue et al. (2009) investigated consumer attitudes toward organic apples. In their study, they clustered consumers into three groups based on the difference in bidding prices for different products. They found that consumers in the "organic-oriented" segment were more concerned about the environment than those in the "conventional-oriented" segment. Hall et al. (2010) explored the profile of the consumer segments that preferred environmental-friendly products. They segmented the consumers into seven groups and found that consumers in the "environmentally conscious" segment showed concern about the environment and were more likely to recycle their products.

Yue et al. (2011) studied regular consumer demand for and attitudes toward native plants and consumer willingness to pay (WTP) for ornamental plants with native and invasive labeling. The results show that, on average, consumers were willing to pay a price premium for plants that were labeled as noninvasive and native and they discounted plants labeled as invasive. Our study is an extension of Yue et al. (2011) and aims to investigate market segmentation among consumers in terms of their preferences and WTP for native and invasive plants. It also explores how consumers in different market segments differ in their sociodemographics and attitudes toward native/invasive plants and invasive plant policies. 


\section{Materials and Methods}

Experimental methods. We evaluated individual preferences for native and invasive ornamental plants using an experimental auction. We used an experimental auction rather than a field study because retailers do not typically label ornamental plants as native or invasive. The experiments were conducted during April of 2008 in the Twin Cities, MN. Six sessions were run with 10 to 15 individuals for a total of 80 participants. Participants were recruited through an advertisement in 13 local newspapers including both urban and suburban communities.

The experimental auctions were conducted in two rounds. In each round, participants simultaneously bid on 10 different ornamental plants in an incentive compatible second-price Vickery auction. A second-price incentive compatible auction is an auction in which the bidders submit sealed bids, and the highest bidder wins the auction paying the second highest bid. Vickery (1961) showed bidders in this type of auction should bid exactly what winning the auction is worth to them. If they bid lower, they risk losing when they would be better off winning. If they bid higher, they risk winning when they would be better off losing. To avoid demand reduction bias (List and Lucking-Reilly, 2000), only one plant from one round was selected as binding after all bids had been submitted. Therefore, participants only had the opportunity to purchase one plant. In the first round, participants were not given information on a plant's native and invasive attributes, although they were given information typically provided by retailers (e.g., size at maturity, flower color, hardiness zone, and height). In the second round, this typical information was complemented with information on the plant's native and invasive attributes.

The 10 plants were selected in species pairs from five different genera: Dianthus, Daucus, Oxalis, Gaura, and Epilobium. Plants in a pair were similar in appearance with one being invasive and the other non-invasive. Therefore, for each pair of plants, the invasive attribute was the most obvious distinguishing attribute. More detailed information about the plants and the experiment is reported by Yue et al. (2011). Of the 80 participants, 76 provided a complete set of bids for all eight plants, which provided 608 bids per round or 1216 total bids for detailed analysis. (Plants numbered one to eight were used in this study to conduct market segmentation analysis because they were similar in size an $4 \mathrm{~d}$ shape. The last pair was dropped because it was considerably larger than the other four pairs and generated different bidding behavior among participants.)

Experimental analysis. We used participants' bidding behavior for the plants in the two rounds to segment participants into different groups. For instance, some participants always increased their second round bids compared with their first round bids if the plants were labeled as native regardless of other plant characteristics, which means these participants were very positive about native attributes. There were also some participants who always lowered their second round bids if the plants were labeled as invasive, which indicates they had negative attitudes toward invasive attributes. The rest of the participants did not systematically change their bids systematically with the additional information about invasive and native attributes.

After we grouped the participants, to further explore the effects of the native and invasive labels on participants' bids, we set up censored random-effect models. Consider the following equation:

$$
\begin{aligned}
P_{j}^{k}= & \alpha_{j}+\beta^{k} X_{j}+\gamma_{j}^{k}+\mu_{j}^{k} \\
k= & \text { plain - labeled, native/invasive } \\
& - \text { labeled },
\end{aligned}
$$

where $P_{j}^{k}$ is participant $j$ 's bid for $k$ th-labeled plant; $\alpha_{j}$ is a linear unmeasured effect that is constant across plant labels for a given individual; and $X_{j}$ is the vector of independent variables. It includes plant attributes such as native and invasive, and interaction effects between plant attributes; $\gamma_{j}^{k}$ is a zero mean random individual effect that captures the correlation among each individual's bids on multiple plants; $\mu_{j}^{k}$ is a zero mean random disturbance across labels and individuals. If we take a difference across labels, we get:

$$
\begin{aligned}
& P_{j}^{\text {native/invasive-labeled }}-P_{j}^{\text {plain-labeled }} \\
& =\left(\beta^{\text {native/invasive-labeled }}-\beta^{\text {plain-labeled }}\right) X_{j} \\
& \quad+\left(\gamma_{j}^{\text {native/invasive-labeled }}-\gamma_{j}^{\text {plain-labeled }}\right) \\
& \quad+\left(\mu_{j}^{\text {native/invasive-labeled }}-\mu_{j}^{\text {plain-labeled }}\right)
\end{aligned}
$$

The unmeasured effect across labels for a given individual disappears. We can condense the coefficients and random terms in Eq. [2] to get:

$$
\begin{aligned}
P_{j}^{\text {native/invasive-labeled }}-P_{j}^{\text {plain-labeled }}= & \beta^{*} X_{j} \\
& +\gamma_{j}^{*}+\mu_{j}^{*}
\end{aligned}
$$

The elements of vector $\beta^{*}$ are expected to be significantly different from zero only if a variable has different effects on the price of the native/invasive-labeled compared with the plain-labeled plants. Otherwise the coefficients would be close to zero; $\gamma_{j}^{*}$ follows a normal distribution with mean zero and SD $\sigma_{\gamma}$; and $\mu_{j}^{*}$ follows a normal distribution with mean zero and SD $\sigma_{\mu}$.

The price participants bid on plants could be censored at zero because the minimum bid for any product was constrained to zero although some participants may have disliked a plant and given it a negative valuation. In Eq. [1], for both plain-labeled and native/ invasive-labeled plants, the bids could be censored at zero. Therefore, we need to take into account the censoring problem when we estimate Eq. [3]. The dependent variable in Eq. [3] is regarded as censored if the bid for the native/invasive-labeled plant is zero, the bid for the plain-labeled plant is zero, or the bids for both plain-labeled and native/invasivelabeled plants are zero. Similar to the study conducted by Huffman et al. (2003) on genetically modified food, there are four cases of censoring: 1) positive bids for both plainlabeled and native/invasive-labeled plantsthe non-censored case; 2) a zero bid for the native/invasive-labeled (censored at zero) plant and a positive bid for the plain-labeled plant - the "true" difference between bid prices is absolutely larger than the difference between the observed bids; 3 ) a positive bid for the native/invasive-labeled plant and a zero bid for the plain-labeled plant (censored at zero) - the "true" difference between bid prices is greater than the difference between the observed bids; and 4) zero bids for both plants - no information can be derived about participants' preference for native/invasive plants. All four cases are correctly taken into account in the censored random effect model in Eq. [3].

To test the hypotheses that the changes in WTP across the two rounds were significantly different between the various segments, we ran Hausman tests (Hausman, 1978) for a significant difference in the estimated coefficients across market segments.

Survey methods. Participants completed a survey in addition to bidding on ornamental plants. The survey consisted of four sections: Section 1 included questions related to gardening experiences; Section 2 consisted of questions related to knowledge about native and invasive plants; Section 3 elicited attitudes (on a 5-point Likert scale) toward native and invasive plants and related policies; and Section 4 asked typical sociodemographic information.

Survey analysis. After dividing participants into three segments based on their bidding behavior, we calculated the means and SDs of sociodemographic and attitudinal variables for each segment. Additionally, we used analysis of variance and two sample $t$ tests to determine if these segments differed significantly in terms of their sociodemographic and attitudinal variables.

\section{Results}

The average age of participants was 49.9 years (Table 1). Participants' mean income level was $\$ 64,800$. The mean educational level was a college diploma. Twenty-four percent of participants were male. The average number of individuals living in a participant's household was 2.46 , whereas the average number of separate purchases the household made for plants or garden-related products in 2007 was $\approx 16$.

Previous studies have shown that $80 \%$ of ornamental plant consumers are female and $73 \%$ of plant purchasers are 40 years and older (Yue and Behe, 2008). Table 1 shows that auction participants were $\approx 50$ years old and most of them were female (74\%). Therefore, we are confident that the participants were reasonably representative of ornamental plant purchasers.

In the questionnaire, we asked participants if they were informed by the sellers the 
plants were native when they bought them in stores. Only $4 \%$ of participants were "always" informed, 18\% were informed "most times," $38 \%$ were "sometimes" informed, 30\% were "seldom" informed, and 10\% were "never" informed. Compared with the native attribute, even fewer people got information about plants' invasiveness when they made purchases. Specifically, $29 \%$ of participants were "never" informed, 38\% were "seldom" informed, 14\% were "sometimes" informed, $11 \%$ were informed "most times," and $8 \%$ were "always" informed.

Market segments. We segmented participants based on their bidding behavior in the two rounds. By comparing participants' bids between a native/invasive-labeled and the plain-labeled plant, we found $34 \%$ of participants always lowered their bids if a plant was labeled as "invasive" (and "non-native") in the second round regardless of plants' other characteristics (size, flower color, height, hardiness zone, etc.). We refer to these participants as "invasive averse." Compared with their bids in the first round, $\approx 16 \%$ of the participants always increased their bids for a plant that was labeled as "native" (and "noninvasive") in the second round regardless of plants' other characteristics. We refer to these participants as "nativists." The third segment consists of the rest of the participants $(50 \%)$ who might increase or decrease their bids in the second round depending on the plants' other characteristics in addition to native/invasive labeling. For example, a participant in the third segment might decrease his or her bid for plant 2 but increase his or her bid for plant 4 although plant 2 and plant 4 were both labeled as "native" and "non-invasive" in the second round. We refer to this segment of participants as the "typical" consumer.

Table 2 shows the demographics and attitudes of the three market segments. We ran analysis of variance (ANOVA) to test if the three segments of participants differed significantly in terms of demographics and attitudes ( $P$ values are shown in the last column). ANOVA test results showed that the three segments differ significantly in their age and income. The average age of nativists was 42.5 years old, whereas invasive averse were 50.4 years old, and typical consumers averaged 51.9 years. In addition to ANOVA, we also conducted $t$ tests to test if the demographics and attitudes differ significantly between any two of the three segments. The $t$ test results showed that the average age of nativists was significantly lower than that of invasive averse and typical consumers. Invasive averse consumers had an average income level of U.S. \$73,800, which was significantly higher than the other two groups of consumers. Nativists had the lowest average income, U.S. \$46.9 thousand (see the end notes of Table 2). ANOVA test

Table 1. Characteristics of experimental auction participants on invasive and native plants in the Minneapolis-St. Paul area.

\begin{tabular}{|c|c|c|c|}
\hline Variable & Definition & Mean & SD \\
\hline$\overline{\text { Age }}$ & Participant's age (years) & 49.93 & 13.02 \\
\hline Income & Household's income level (\$000s) & 64.80 & 27.54 \\
\hline Education & $\begin{array}{l}\text { Participant's education level } \\
\qquad \begin{aligned} 1 & =\text { Some high school or less }(2 \%) \\
2 & =\text { High school diploma }(5 \%) \\
3 & =\text { Some college }(28 \%) \\
4 & =\text { College diploma }(45 \%) \\
5 & =\text { Some graduate school }(8 \%) \\
6 & =\text { Graduate degree }(12 \%)\end{aligned}\end{array}$ & 3.86 & 1.12 \\
\hline Gender & 1 if male; 0 if female & 0.24 & 0.43 \\
\hline Household & Number of people in participant's household & 2.46 & 1.39 \\
\hline Purchase & $\begin{array}{l}\text { Number of separate purchases the household made for plants or } \\
\text { garden-related products in } 2007\end{array}$ & 15.93 & 11.29 \\
\hline
\end{tabular}

results did not suggest significant differences among the three groups in terms of their gender but $t$ test results showed that nativists had a significantly higher percentage of male participants than typical consumers. Specifically, $42 \%$ of nativists were male but only $18 \%$ of typical consumers were male.

The three segments of participants also differ in their attitudes toward native/invasive plant attributes and related policies based on ANOVA. In the questionnaire, we asked participants to indicate their level of agreement with several statements on a 1 to 5 Likert scale with 1 meaning "strongly disagree" and 5 meaning "strongly agree." Three segments of participants were significantly different in their degree of agreement with the statement " 'Native' is mainly a marketing gimmick." Invasive averse individuals had a significantly higher level of agreement with this statement than typical consumers. The three segments of participants differed significantly in their degree of agreement with the statement "Native plants help reduce air pollution." Invasive averse had a significantly lower degree of agreement with this statement than the other two groups of participants. Invasive averse also had a significantly lower degree of agreement with the statement "Native plants promote biodiversity and stewardship of our natural heritage" than typical consumers. Compared with typical consumers, invasive averse had a higher level of agreement with the statement "The government should restrict the entry of plants into U.S. until they are proven to be non-invasive."

Censored regression estimation results for the three segments. The censored models with random individual effects for the three segments of participants were estimated using a maximum likelihood procedure in Stata 10.0 (Stata Corp., College Station, TX). Censored regression results from fitting Eq. [3] with an individual random effect to explain the difference in bid prices between the native/invasivelabeled and plain-labeled plants are shown in Table 3. Hausman tests rejected pooling the data across market segments with $P$ values $<0.01$.

Table 2. Sociodemographics and attitudes of the three market segments of experimental auction participants on invasive and native plants in the MinneapolisSt. Paul area.

\begin{tabular}{|c|c|c|c|c|c|c|c|}
\hline \multirow[b]{2}{*}{ Variable } & \multicolumn{2}{|c|}{ Nativists $(16 \%)$} & \multicolumn{2}{|c|}{ Invasive averse $(34 \%)$} & \multicolumn{2}{|c|}{ Typical $(50 \%)$} & \multirow{2}{*}{$\begin{array}{l}\text { ANOVA } \\
\text { test } P \text { value }\end{array}$} \\
\hline & Mean & SD & Mean & SD & Mean & SD & \\
\hline \multicolumn{8}{|l|}{ Demographics } \\
\hline Age & 42.50 & 16.07 & 50.42 & 11.10 & 51.88 & 12.30 & $0.09^{\mathrm{z}, \mathrm{y}}$ \\
\hline Gender & 0.42 & 0.50 & 0.25 & 0.43 & 0.18 & 0.38 & $0.23^{y}$ \\
\hline Income & 46.88 & 26.79 & 73.85 & 27.78 & 64.75 & 24.91 & $0.02^{\mathrm{z}, \mathrm{y}}$ \\
\hline \multicolumn{8}{|l|}{$\begin{array}{l}\text { Attitudes (degree of agreement, } 1=\text { strongly } \\
\text { disagree, } 5=\text { strongly agree) }\end{array}$} \\
\hline "Native" is mainly a marketing gimmick & 2.00 & 0.92 & 2.42 & 1.04 & 1.93 & 0.93 & $0.15^{\mathrm{x}}$ \\
\hline Native plants help reduce air pollution & 3.75 & 0.93 & 2.92 & 0.81 & 3.72 & 0.87 & $<0.01^{\mathrm{z}, \mathrm{x}}$ \\
\hline $\begin{array}{l}\text { Native plants promote biodiversity and stewardship of our } \\
\text { natural heritage }\end{array}$ & 3.92 & 0.96 & 3.67 & 0.90 & 4.08 & 0.88 & $0.23^{\mathrm{x}}$ \\
\hline $\begin{array}{l}\text { The government should restrict the entry of plants into United } \\
\text { States until they are proven to be non-invasive }\end{array}$ & 4.17 & 0.69 & 4.50 & 0.71 & 4.00 & 1.25 & $0.19^{\mathrm{x}}$ \\
\hline
\end{tabular}

${ }^{z}$ Test the difference between nativists and invasive averse, $t$ test $P<10 \%$.

y Test the difference between nativists and typical consumers, $t$ test $P<10 \%$.

${ }^{\mathrm{x}}$ Test the difference between invasive averse and typical consumers, $t$ test $P<10 \%$.

ANOVA $=$ analysis of variance. 
Table 3. Censored regression estimation results for the three segments of experimental auction participants on invasive and native plants in the Minneapolis-St. Paul area.

\begin{tabular}{|c|c|c|c|c|c|c|}
\hline \multirow[b]{2}{*}{ Variables } & \multicolumn{2}{|c|}{ Nativists $(16 \%)$} & \multicolumn{2}{|c|}{ Invasive averse (34\%) } & \multicolumn{2}{|c|}{ Typical (50\%) } \\
\hline & Coefficient & SE & Coefficient & SE & Coefficient & SE \\
\hline Invasive & $-0.90^{* z}$ & 0.44 & $-1.89 * *$ & 0.33 & -0.57 & $\overline{0.32}$ \\
\hline Native & $0.83 *$ & 0.43 & 0.39 & 0.32 & -0.004 & 0.31 \\
\hline Native*invasive & $-1.35^{*}$ & 0.61 & $-0.91 *$ & 0.47 & -0.72 & 0.44 \\
\hline Intercept & 0.42 & 0.41 & -0.33 & 0.32 & 0.29 & 0.28 \\
\hline \multicolumn{7}{|c|}{ Random individual effect } \\
\hline$\hat{\underline{\sigma}}_{\gamma}$ & $0.48 * *$ & 0.18 & $0.81 * *$ & 0.16 & 0.00 & 0.17 \\
\hline
\end{tabular}

${ }^{2 *}$, and $* *$ denote significance at the 0.05 and 0.01 levels, respectively.

The estimation results indicate that nativists were willing to pay the highest premium for the "native" attribute, which was $\approx \$ 0.83$ per plant. The price premiums for the "native" attribute by invasive averse and typical consumers were not significantly different from zero. Invasive averse consumers discount the "invasive" attribute the most, $\$ 1.89$ per plant, followed by nativists, $\$ 0.90$ per plant. The "native" and "invasive" attributes did not significantly affect the typical consumers' WTP for a plant. We did find a negative and significant interaction between the "native" and "invasive" attributes for all three segments. Participant sociodemographic effects on WTP were captured using the random individual effects. The correlation between the multiple bids made by the same participant was significant at 0.01 for nativists and invasive averse, but was not significant for the typical consumers.

\section{Discussion}

The results of this research offer several useful insights for the horticulture industry and policymakers concerned about the spread of invasive plant species. First, market segmentation analysis showed that distinct consumer segments with different preferences for "native" and "invasive" plants do exist. A relatively small group of consumers demonstrate a strong interest in native plants. They strongly believe that native plants can help reduce air pollution and promote biodiversity and stewardship of our natural heritage. Another group of consumers is very sensitive to and dislikes invasive plants and they strongly support stricter invasive policies. The third group of consumers, which consists of the largest market segment, does not care very much about the "native" or "invasive" attributes. Their purchase decision is much more dependent on other plant characteristics.

Second, the experimental auction allows us to estimate the price premium or discount the three segments of consumers might place on ornamental plants if native or invasive plants were labeled. In our experimental auction, nativists were willing to pay $\$ 0.83$ more for native plants. The horticulture industry seems likely to agree on native labels and therefore can charge a premium. Both nativists and invasive averse consumers, representing half of the market share, discounted the invasive attribute when it was labeled. The horticulture industry might oppose invasive labels, but stakeholders selling non-invasive plants in the industry may see new opportunities to supply and label non-invasive plants at a premium. Without native labels, a consumer pays a lower price for native plants than he or she would, so native labels will benefit suppliers of native plants. Conversely, without the invasive labels, a consumer pays a higher price for invasive plants than he or she otherwise would. Third, we found that consumers in different market segments differ in their sociodemographics and attitudes toward "native" and "invasive" attributes. An interesting finding is that nativists were mostly younger, had relatively lower income levels, and more of them were male compared with the rest of consumers in the market. Some earlier studies found that young consumers (18 to 34 years old) were aware and concerned about the environment and sustainability and reported that "green" purchases that are beneficial to environment are "trendy" (Adweek 2008). The fact that consumers primarily associate native attributes with the environment and that younger consumers are more concerned with the environment may explain why younger consumers prefer native plants more than older consumers. Invasive averse had relatively higher income levels than others and agreed more with strict policies on invasive plants.

These findings have important marketing and policy implications. Our study estimated the market share and the price premium or discount associated with "native" or "invasive" attributes for each segment, which can help inform the horticulture industry on how labeling of "native" or "invasive" attributes could potentially affect the sales of ornamental plants. Plant suppliers with different target markets might be affected by the native/ invasive labels in different ways. For instance, suppliers with younger consumers whose incomes are relatively low as their target market might be most benefited from labeling "native" plants, whereas suppliers whose target market are female consumers with higher income are most likely to be hurt by labeling "invasive" plants. From the government policy perspective, labeling invasive plants could potentially change the behavior of some consumers, but there still exists a significantly large market share $(50 \%)$ that might not be affected by the native/invasive labeling. Other policies need to be investigated to promote native plants and restrict the spread of invasive plants.

\section{Conclusions}

This study has demonstrated that labeling ornamental plants as native or invasive would have different effects on different market segments. Implications of the study are notable given increasing consumer concerns about the environment. Given that a segment of consumers $(16 \%)$ in the Twin Cities region revealed a positive premium for native plants, a store that labels the native plants might be able to attract the nativists and glean a higher profit from them. Because 34\% consumers revealed a significant discount for invasivelabeled plants, labeling the invasive attributes might decrease the purchases of invasive plants by these invasive averse individuals. We found a large market share might not be affected by the invasive labeling, which suggests other policies may need to be investigated to substantially restrict the spread of invasive plants. Supply-side instead of demand-side interventions should be explored to control the purchases of invasive plants by the typical consumer. Given the fact that there exists market segmentation among consumers in terms of their preferences for invasive plants, a combination of invasive labeling and supply-side interventions should be applied to exercise greater control over the spread of invasive plants through the horticultural trade.

As mentioned earlier, the experimental auction was conducted in Twin Cities area of Minnesota. The sample of consumers is representative of Minnesota or Midwestern ornamental plant consumers rather than the whole U.S. population. Therefore, the extrapolation of the results to other regions should be made with caution. Future research is needed to examine the robustness of these results by replicating experiments in other U.S. areas. Other future research might also be focused on consumer reactions to more detailed information about native plants and invasive plants.

\section{Literature Cited}

Adams, D.C., D.J. Lee, S. Bucaram, and A.N. Bwenge. 2007. The impact of invasive plants on the recreational value of Florida's coastal, freshwater and upland natural areas. Selected Paper prepared for presentation at the American Agricultural Economics Association Annual Meeting, Portland, Oregon.

Adweek. 2008. 19 Mar. 2012. <http://www.adweek. com/aw/content_display/news/agency/e3ibfc 872c5b952c69b2a630ac11ccbfbbb>.

Anderson, N.O. and P.D. Ascher. 1993. Male and female fertility of loosestrife (Lythrum) cultivars. Journal of the ASHS 118:851-858.

Anderson, N.O., S.M. Galatowitsch, and N. Gomez. 2006b. Selection strategies to reduce invasive potential in introduced plants. Euphytica 148:203206.

Anderson, N.O., N. Gomez, and S. Galatowitsch. 2006a. A non-invasive crop ideotype to reduce invasive potential. Euphytica 148:185-202.

Brzuszek, R.F., R.L. Harkess, and S.J. Mulley. 2007. Landscape architects' use of native plants in the southeastern United States. HortTechnology 17:78-81.

Gagliardi, J.A. and M.H. Brand. 2007. Connecticut nursery and landscape industry preferences for solutions to the sale and use of invasive plants. HortTechnology 17:39-45.

Galatowitsch, S.M., N.O. Anderson, and P.D. Ascher. 1999. Invasiveness in wetland plants 
in temperate North America. Wetlands 19:733755 .

Groves, R.H. 1998. Recent incursions of weeds to Australia 1971-1995. CRC for Weed Management Systems Technical Series 3. p. 1-7.

Hall, C.R., B.L. Campbell, B.K. Behe, C. Yue, R.G. Lopez, and J.H. Dennis. 2010. The appeal of biodegradable packaging to floral consumers. HortScience 45:583-591.

Hausman, J.A. 1978. Specification tests in econometrics. Econometrica 46:1251-1271.

Huffman, W.E., J.F. Shogren, M. Rousu, and A. Tegene. 2003. Consumer willingness to pay for genetically modified food labels in a market with diverse information: Evidence from experimental auctions. Journal of Agricultural and Resource Economics 28:481-502.

Kelley, K.M., J.R. Stumpf, J.C. Sellmer, and R.M. Bates. 2005. Invasive plant species: Consumer awareness, knowledge, and expectations. Hort Science 40:1136.

Kim, C.S., D. Lee, G. Schaible, and U. Vasavada. 2007. Multiregional invasive species management: Theory and an application to Florida's exotic plants. Journal of Agricultural and Applied Economics 39:111-124.

Laroche, M., J. Bergeron, and G. Barbaro-Forleo. 2001. Targeting consumers who are willing to pay more for environmentally friendly products. J. Consum. Mark. 18:503-520.

List, J. and D. Lucking-Reilly. 2000. Demand reduction in multi-unit auctions: Evidence from a sportscard field experiment. Amer. Econ. Rev. 90:961-972.

Mack, R.N. 2003. Plant naturalizations and invasions in the eastern United States: 1634-1860. Ann. Mo. Bot. Gard. 90:77-90.

Mack, R.N. 2005. Predicting the identity of plant invaders: Future contributions from horticulture. HortScience 40:1168-1174.

Mack, R.N. and M. Erneberg. 2002. The United States naturalized flora: Largely the product of deliberate introductions. Ann. Mo. Bot. Gard. 89:176-189.

Moffitt, L.J. and C.D. Osteen. 2006. Prioritizing invasive species threats under uncertainty. Agricultural and Resource Economics Review 35:41-51.

Peters, W.L., M.H. Meyer, and N.O. Anderson. 2006. Minnesota horticultural industry survey on invasive plants. Euphytica 148:75-86.

Randall, J.M. and J. Marinelli (eds.). 1996. Weeds of the global garden. Brooklyn Botanic Garden, Brooklyn, NY.

Reichard, S. 2005. The tragedy of the commons revisited: Invasive species. Front. Ecol. Environ 3:109-110.
Reichard, S.H. and P. White. 2001. Horticulture as a pathway of invasive plant introductions in the United States. Bioscience 51:103-113.

Russo, M.V. and P.A. Fouts. 1997. A resourcebased perspective on corporate environmental performance and profitability. Acad. Manage. J. 40:534-559.

Schaffner, D.J., W.R. Schroder, and M.D. Earle. 1998. Food marketing: An international perspective. WCB McGraw-Hill, Boston, MA.

Vickery, W. 1961. Counterspeculation, auctions, and competitive sealed bids. J. Finance 16:8-37.

Waterstrat, J., J. Deeds, and R.L. Harkess. 1998. Assessment of the native plants market in the southeastern United States. HortScience 33:603.

Yue, C., F. Alfnes, and H.H. Jensen. 2009. Discounting spotted apples: Investigating consumers' willingness to accept cosmetic damage in an organic product. Journal of Agricultural and Applied Economics. 41:29-46.

Yue, C. and B.K. Behe. 2008. Estimating U.S. consumers' choice of floral retail outlets. HortScience 43:764-769.

Yue, C., T. Hurley, and N. Anderson. 2011. Do native and invasive labels affect consumer willingness to pay for plants? Evidence from experimental auctions. Agr. Econ. 42:195-205. 